\title{
STUDY OF PHARMACEUTICAL INVENTORY CONTROL SYSTEM IN SEVERAL PHARMACIES IN KARANGASEM, BALI
}

\author{
I Made Ari Anata ${ }^{1}$, I Made Agus Gelgel Wirasuta ${ }^{1}$ \\ ${ }^{1}$ Department of Pharmacy, Faculty of Math and Science, Udayana University, Jimbaran, Bali, \\ Indonesia
}

Corresponding author email: gelgel.wirasuta@unud.ac.id

\begin{abstract}
Background: The control of pharmaceutical products is one of the pharmaceutical services at the Pharmacy that is regulated in Permenkes RI No. 73 of 2016. The pharmacy control of each pharmacy must always apply the principles stated in the Good Pharmacy Practice (GPP) guidelines. GPP is a pharmaceutical practice that responds to the needs of people who use pharmacist services to provide optimal and evidence-based care. Objective: This study aims to determine the system of one of the pharmaceutical service standards, namely the control of pharmaceutical products in several pharmacies in Karangasem, Bali. Methods: This type of research is observational descriptive. Data retrieval was carried out in a retrospective manner related to the pharmaceutical product control system in the form of an order or procurement, dispensing, and handling system. Results: Most pharmacies are researched to apply the same control system in the procurement and spending of pharmaceutical products. Only the pharmaceutical product system for handling parts has a slight difference in each pharmacy. Conclusion: The pharmaceutical product control system in several Karangasem pharmacies has many similarities in terms of procurement and dispensing.
\end{abstract}

Keywords: forensics, control, pharmaceutical products, pharmacies, pharmacists

\section{INTRODUCTION}

Forensic pharmacy is the application of pharmaceutical related to legal issues. Forensic pharmacy covers clinical aspects, distribution, administration, and basic science of pharmaceutical science. ${ }^{[1],[2]}$ Drug management is a series of activities that involve aspects of planning, procurement, storage, and distribution, of drugs that are managed optimally. ${ }^{[3]}$

Control of pharmaceutical products is regulated in the Republic of Indonesia Ministerial Regulation No. 73 of 2016 concerning Pharmaceutical Service Standards at Pharmacies in Article 3 which are mentioned: (Paragraph 1) Pharmaceutical service standards at pharmacies include standards: management of pharmaceutical products, medical devices, and consumable medical materials, clinical pharmaceutical services. (Paragraph 2) Management of pharmaceutical products, medical devices, and consumable medical materials as referred to in paragraph (1) letter a includes a. planning; b. procurement; c. reception; d storage; e. annihilation; f. control; and g; recording and reporting. ${ }^{[4]}$

Control is carried out to maintain the type and amount of supplies according to service needs, through the ordering system or procurement, storage, and dispensing systems. It aims to avoid the occurrence of excess, deficiency, emptiness, damage, expiration, loss, and return of orders. Inventory control is done using a stock card either manually or electronically. The stock card should at 
least contain the name of the pharmaceutical product, the expiration date, the amount of revenue, the amount of dispensing, and the remaining inventory. ${ }^{[5]}$

Inventory control is an activity to ensure the achievement of the desired targets following the strategies and programs that have been set so that there are no advantages and disadvantages or vacancies in pharmaceutical products. Drug inventory control consists of:

1. Control of availability

Vacancies or shortages of pharmaceutical products in pharmacies can occur due to several things:

- improper planning

- changes in government policies (for example, changes in e-catalogs, so that pharmaceutical products that were planned the previous year are not included in the catalog of new pharmaceutical products); and

- the following are some steps that pharmacists can take to prevent or overcome pharmaceutical deficiencies or gaps:

- Conduct planning analysis before ordering or purchasing pharmaceutical products.

- Replace trademark drugs with generic drugs with the same active components or other trademark drugs with the approval of the doctor and/or patient.

- Perform stock taking of pharmaceutical, BMHP, and medical devices regularly at least once in 6 (six) months. Specifically, for Narcotics and Psychotropic stock taking, it is conducted regularly

- At least once in 1 (one) month. ${ }^{[5]}$

2. Control of use

Control of the use of pharmaceutical products is carried out to determine the amount of receipt and use of pharmaceutical products to ascertain the number of needs of pharmaceutical products in one period. ${ }^{[5]}$

3. Handling in the event of damage, recall, and expiration. ${ }^{[5]}$
The eradication and withdrawal of drugs that cannot be used must be carried out by the provisions of the legislation in force. ${ }^{[5]}$

Good Pharmacy Practice (GPP) is a pharmaceutical practice that responds to the needs of people who use pharmacist services to provide optimal and evidence-based care. This GPP must be needed as a standard quality standard guideline for every pharmacist who works in the pharmaceutical field. ${ }^{[6]}$

GPP includes standards that often exceed the standards set by national law. Furthermore, the law rarely provides precise instructions on how services must be produced to meet requirements. Therefore, pharmacies have a role in setting the standards required for GPP, which include a quality management framework and a strategic plan for service development. It is also recognized that in developing national standards for GPP, attention must be needed to the needs of users of health care services and the capacity of national health care systems to support these services. ${ }^{[6]}$

Minimum national standards for each activity are based on processes that need to be relevant and precisely defined according to the local needs of the pharmacy, environmental aspirations, and national professions. All pharmacies must also adjust their roles and functions according to their own needs. This activity can be further defined and measured by establishing indicators of good practice in the national context and can be burdened by priorities of actual practice settings. ${ }^{[6]}$

Karangasem is a district located on the easternmost tip of the island of Bali. Karangasem has 8 sub-districts, 75 villages, and 3 villages. Karangasem is bordered by Klungkung, Buleleng, and Bangli districts. ${ }^{[7]}$ Regarding the control of pharmaceutical products in pharmacies in the Karangasem area, no research has been found that shows the control systems of pharmaceutical products in this area. 
Based on the problem above, this research was conducted to find out how the differences and similarities in the pharmaceutical product control system, namely the arrangement of the order or procurement system, dispensing, handling related to excess, deficiency, emptiness, damage, and expiration in several pharmacies in Karangasem area. Besides, this study aims to link drug control in several pharmacies whether it meets the requirements of Good Pharmacy Practice. The next objective of this research is to obtain more in-depth information about the pharmaceutical product control system that is in line with the GPP in several pharmacies in the Karangasem area, Bali.

\section{RESEARCH METHODS}

This research is a descriptive observational study. Sources of information came from Pharmacists and Pharmacist Assistants in pharmacies A, B, C, and D which are located in Karangasem District, Karangasem Regency, Bali. Data collection techniques were carried out by interviewing Pharmacists and Pharmacist Assistants outside of service hours. The research variables are the system of drug procurement, drug dispensing, and drug handling.

Primary data was obtained by interviewing directly to interviewees and recording all data. This type of research data is retrospective, i.e. research conducted now (June 2020) based on data collection from the past. Data were analyzed using descriptive analysis in the form of a table.

\section{RESULT AND DISCUSSION \\ Pharmaceutical Products Procurement at the Pharmacy}

The results of interviews about the procurement of pharmaceutical products at the four pharmacies use a system of order letters (also called Surat Pesanan or SP) addressed to the distributor of pharmaceutical products (also called
Perusahaan Besar Farmasi or PBF). Drug procurement system to control the absence of stock vacancies is done by estimating the stock that is felt to be exhausted on a certain day so that it is prevented by placing an order for the drug before the day arrives. On average, all four pharmacies make orders every 2-3 days.

How to conduct drug procurement for distributors in each pharmacy is different considering the Karangasem area is located far from downtown Denpasar. The difference lies in how to order drugs to the distributor. The four pharmacies make an order by taking photos of $S P$ and then sending it to the online distributor. The distributor usually uses the services of an expedition to deliver the ordered medicine. The expedition will come with medicine about 2-3 days after sending the $S P$ photo. When the expedition arrives, the $S P$ will be deposited. However, often the expedition only brought the medicine without $S P$ payment to the distributor.

\section{Dispensing of Pharmaceutical Products at the Pharmacy}

The results of interviews with pharmacies have different drug dispensing values. The value of dispensing in question is the percentage between drug dispensing with a prescription and drug dispensing without a prescription. The percentage of drug dispensing by prescription and without a prescription can be seen in table 1 .

The difference in the percentage of each pharmacy can be caused by geographical factors of the pharmacy. Like pharmacy B, which is located in front of Karangasem District Hospital. Patients after undergoing the examination and bring a prescription from the hospital, can go directly to the pharmacy so that the drug that comes out of the pharmacy has the same percentage between without a prescription and by prescription. The other three pharmacies which are located far from health services are more dominant to have non-prescription drug dispensing. 
Table 1. Percentage of drugs out of each pharmacy

\begin{tabular}{|c|c|c|}
\hline \multirow{2}{*}{ Pharmacy } & \multicolumn{2}{|c|}{ Comparison of drugs out of the pharmacy } \\
\cline { 2 - 3 } & Without a prescription & With prescription \\
\hline A & $60 \%$ & $40 \%$ \\
\hline B & $50 \%$ & $50 \%$ \\
\hline C & $65 \%$ & $35 \%$ \\
\hline D & $90 \%$ & $10 \%$ \\
\hline
\end{tabular}

Table 2. Comparison of types of drugs that come out of the pharmacy

\begin{tabular}{|c|c|c|c|}
\hline \multirow{2}{*}{ Pharmacy } & \multicolumn{3}{|c|}{ Comparison of types of drugs out of the pharmacy } \\
\cline { 2 - 4 } & OTC & Prescribing Medicine & Psychotropic drugs \\
\hline A & $50 \%$ & $30 \%$ & $20 \%$ \\
\hline B & $50 \%$ & $20 \%$ & $6 \%$ \\
\hline C & $65 \%$ & $35 \%$ & - \\
\hline D & $90 \%$ & $10 \%$ & - \\
\hline
\end{tabular}

The interviews also got a comparison of the types of drugs that came out of the pharmacy. The types of drugs in question are Bebas (drugs freely available to the public), Terbatas (drugs available to the public only through licensed pharmacy), Keras (drugs available to the public on prescription only), and psychotropic drugs. Values are presented in percentage form, which can be seen in table 2. Pharmacy $\mathrm{C}$ and $\mathrm{D}$ do not store psychotropic drugs so there is no dispensing for psychotropic drugs that must be controlled by pharmacies.

An important aspect of controlling drug dispensing is how the drug is regulated so that no stockpiles of medicine occur. The drug dispensing system is regulated by each pharmacy. The results of the interview stated that the dispensing system can be through a pharmacist's recommendation or a pharmacist's assistant to patients who need medicine so that it can be recommended with drugs whose stock has accumulated but still pay attention to the patient's pathological factors and the appropriateness of therapy from the recommended drug.

\section{Handling of Pharmaceutical Products at the Pharmacy

Handling the advantages and
disadvantages of drug stocks

The handling of excess drug stocks in the four pharmacies has the same system and has the same thing as a system for controlling drug dispensing. Excessive drugs will be recommended to sell first. Handling related to deficiencies has in common in the four pharmacies that are immediately to place an order related to the lack of drugs.

\section{Management of drug loss}

The results of the interviews conducted stated that the four pharmacies had never lost a drug (theft/smuggling of drugs) by the buyer or employee. Drug loss due to data errors on the computer with the physical amount of the drug is almost experienced by all these pharmacies. Which on the computer shows the stock is still there but when it is examined the drug is empty or nonexistent. Handling is done that is improving data on the computer so that no errors occur next.

The handling of discrepancies in the physical amount of the drug with the number of stocks listed on the computer by each pharmacy is different. Pharmacy A prevents the discrepancy between the physical amount of the drug and the amount of stock on the computer by making notes in the form of a book placed near the drug to be taken. Each time you take medicine, the book will be filled with the number of drugs taken every day. 
Table 3. The percentage of the drug has expired the last 3 months from the entire drug stock

\begin{tabular}{|c|c|}
\hline Pharmacy & Percentage of expired drugs stored at pharmacy \\
\hline A & $10-20 \%$ \\
\hline B & $0 \%$ \\
\hline C & $2-3 \%$ \\
\hline D & $10 \%$ \\
\hline
\end{tabular}

The purpose of this is to avoid data discrepancies due to factors that incorrectly enter data or forget to enter (input) the name of the drug that has been purchased. At the end of the day, checking the notebook with the data on the computer will then correct the data on the computer before using it for the next day.

The other three pharmacies $(\mathrm{B}, \mathrm{C}$, and $\mathrm{D})$ do not do prevention. These three pharmacies do the treatment by checking the physical amount of the drug then fixing the data on the computer. This examination is carried out on average every 3 month.

\section{Expired Medicine Handling}

The interview results were obtained in the form of a percentage of drugs that have expired in the last three months. The results can be seen in table 3. All pharmacies handle the issue of expired drugs by returning to PBF. All four pharmacies make returns on pharmaceutical products three months before they expire. Returns for products are carried out under procedures established by the PBF.

According to informants from the four pharmacies, returns can only be done if the box of the drug strip is still sealed. Suppose a unit-shaped drug such as a bottle must meet a minimum amount to be able to do returns. If the provisions stipulated by PBF are not met, the pharmacy uses various methods to deal with this. Pharmacies A, B, and $\mathrm{C}$ will deal with by recommending drugs that are approaching expiry first with the aim of the drug will run out before the expiry period. Only D pharmacy do treatment with drug destruction when the expiry date arrives. Pharmacy D does destruction by burying pharmaceutical products in a hole that has been provided. Pharmacy A, B, and
$\mathrm{C}$ prefer to return expired drugs to $\mathrm{PBF}$ rather than destruct them. From the table above shows pharmacy $B$ has the smallest percentage of expired drugs. It happened as previously discussed related to the location of the pharmacy B in front of the hospital so that a high level of sales can reduce excess stock to prevent the expiration of stored pharmaceutical products. By the drug control, all pharmacies almost have the same drugs control. The location of pharmacy B makes it better at handling expired drugs than others.

\section{Flow Chart of Four Pharmacies Inventory Control}

All drug control in the four pharmacies can be presented with a flowchart of pharmaceutical supply procurement through its handling. This flow diagram serves as a brief description of the process of procuring, dispensing, and handling far-off products from the four pharmacies. The flow chart can be seen in the following figure 1 .

\section{Linkages between Pharmacy Inventory Control and Good Pharmacy Practice}

GPP requires that a pharmacist's first concern in all settings is patient welfare. GPP requires that the essence of pharmaceutical activity is to help patients with the best use of medicines. Basic functions include the supply of medicines and health care products with guaranteed quality, the provision of appropriate information and advice to patients, the administration of drugs if needed, and the monitoring of the effects of drug use. ${ }^{[6]}$

GPP requires that an integral part of the contribution of pharmacists is the promotion of rational and economic prescribing, as well 
as expenses. GPP requires that the goals of each pharmaceutical service element are relevant to patients, clearly defined, and effectively communicated to all involved. ${ }^{[6]}$

The relationship between the control of pharmaceutical products with GPP is very close. Without meeting the minimum standards of GPP, the control of pharmaceutical products cannot be said to be feasible. The following will explain the relationship of stock control in the flow chart with GPP.

The procurement process always considers stock availability. Reducing stock is immediately ordered by making an order letter signed by the pharmacist at the pharmacy. Various types of submission of order letters can be seen there are 3 types, namely through social media online with photos of the order letter sent online, through an expedition to send the order letter as well as through sales distributors who coincide at that time sent orders to the pharmacy in question.

The link between the procurement procedures according to the flow chart meets the GPP requirements on the requirement that the pharmacist responsible for procurement must be supported by a strong quality assurance principle. ${ }^{[6]}$ The intended guarantee is that illegal drugs such as counterfeit and unlicensed drugs may not enter the system in the pharmacy. Therefore, the procurement of drugs must always check the order of medicines received before storage or display according to the flow chart above.

Another requirement is that pharmacists must make contingency plans for shortages of medicines and purchases in an emergency. ${ }^{[6]}$ Requirements for procurement of supplies in this emergency category are met because of the medication orders made. Ordering of drugs is done before the relevant drug empties. Orders are also made online by utilizing social media as an alternative to ordering supplies to PBF which are located far from the pharmacy. With that, the order will be received a few minutes by $\mathrm{PBF}$ so that orders can be delivered faster than waiting for sales or couriers to take orders to the pharmacy.

The dispensing of pharmaceutical products at the pharmacy according to the diagram above is clearly explained. Pharmaceutical products come out of the pharmacy in 2 ways, namely by prescription and without a prescription from a doctor. Drug dispensing without a prescription at the pharmacy also has a difference. One of them in terms of types of consumers purchasing drugs. Usually, consumers will take the medicine directly on the shelf. The medicines that are taken are usually free and limited drugs but there are also taking traditional medicines and cosmetics directly. Other types of consumers will ask whether available drugs that are usually used in dealing with the disease. The pharmacist will get the drug (usually hard medicine) with the record that the drug has been used or brought a medication container by the patient.

Pharmacist control in terms of dispensing drugs must meet the GPP requirements ie the pharmacist must ensure that all products are handled and distributed to patients by ensuring the reliability and safety of drug supplies.

Handling of pharmaceutical products is also required by the GPP i.e. pharmacists must ensure that regular monitoring of drug supplies is carried out and must always include drug samples in the inspection process for expiration and elimination of obsolete stock. Pharmacists must also ensure that medical products are recalled and immediately stored separately for further disposal and prevented from further dispensing or distribution at the pharmacy. ${ }^{[6]}$ Following the flow diagram above, the handling of pharmaceutical products has met the GPP requirements, i.e. the products will always be monitored and checked expired. A. If expiry has arrived, the pharmacy will be culling for stocks that cannot be done return and return if the product is allowed returns by the PBF. 


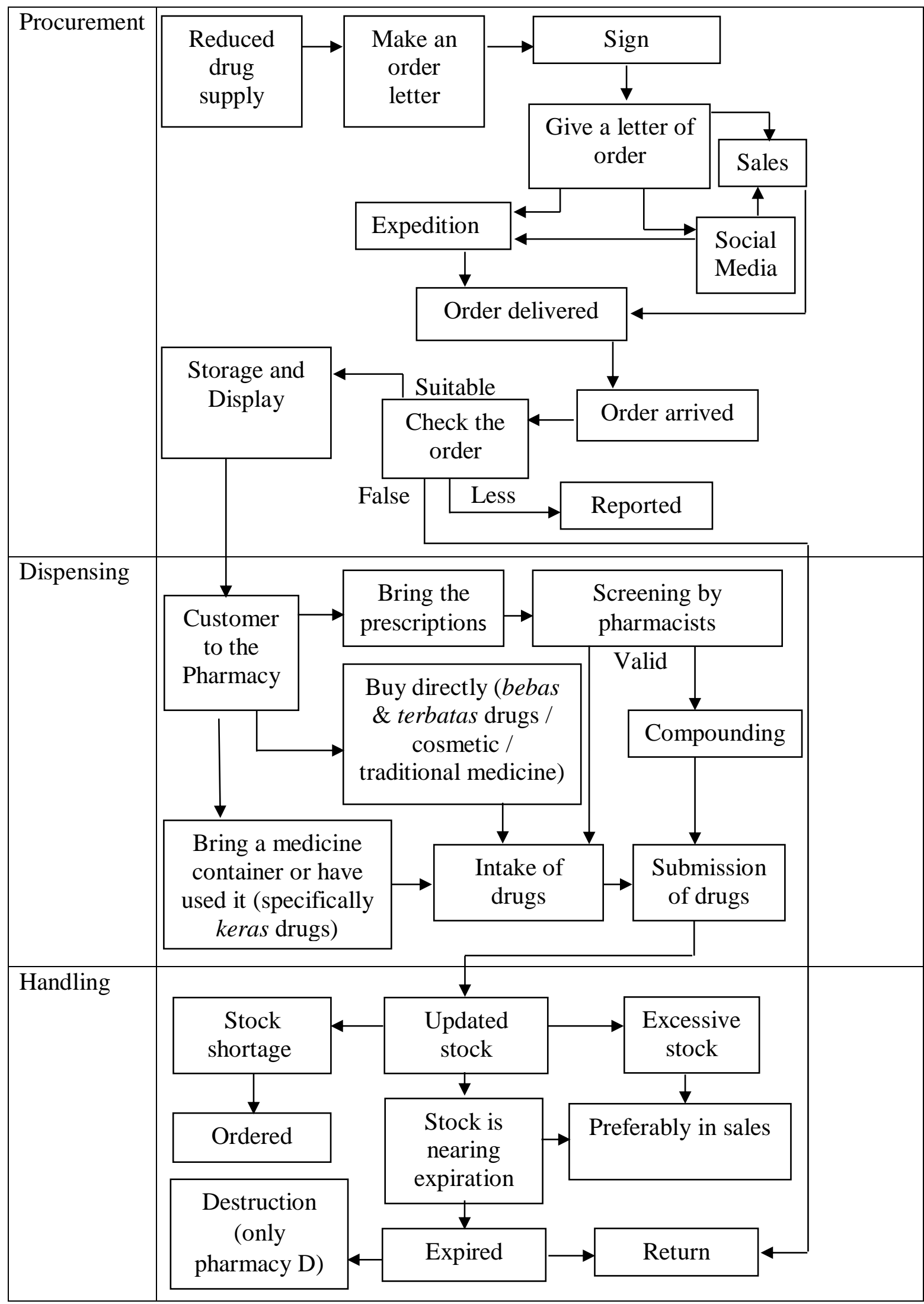

Figure 1. Flow chart of all four pharmacies inventory control 


\section{CONCLUSION}

The pharmaceutical product control system in several Karangasem pharmacies has many similarities in terms of procurement and dispensing. There was only a slight difference in the handling of pharmaceutical products at each pharmacy. Overall, the control of pharmaceutical products has met the minimum standards of Good Pharmacy Practice (GPP). With the fulfillment of this GPP, the pharmaceutical product control system in several pharmacies in the Karangasem area is feasible.

\section{CONFLICT OF INTEREST}

This paper was written independently. All authors disclose no financial or personal relationships with other people or organizations that could inappropriately influence the work.

\section{ACKNOWLEDGEMENT}

Thank you to the leadership, pharmacists, and assistant pharmacists of the four pharmacies who have been willing to be a resource in research until the completion of this research.

\section{REFERENCES}

1. Anderson, P. D. 2000. An Overview of Forensic Pharmacist Practice. Journal of Pharmacy Practice. 13(3): 179-186.

2. Anderson, P. D. and O'Donnell J. T. 2005. The Forensic Pharmacist. In: O'Donnell J. T. ed. Drug Injury: Liability, Analysis and Prevention. $2^{\text {nd }}$ ed. Tucson, AZ: Lawyers and Judges Publishing Company, Inc.

3. Mangindara, Darmawansyah, Nurhayani, dan Balqis. 2012. Analisis Pengelolaan Obat di Puskesmas Kampala Kecamatan Sinjai Timur Kabupaten Sinjai Tahun 2011. Jurnal Administrasi dan Kebijakan Kesehatan. 1(1): 1-55.

4. Menkes RI. 2016. Peraturan Menteri Kesehatan Republik Indonesia Nomor 73 Tahun 2016 Tentang Standar
Pelayanan Kefarmasian di Apotek. Jakarta: Menteri Kesehatan Republik Indonesia.

5. Kemenkes RI. 2019. Petunjuk Teknis Standar Pelayanan Kefarmasian di Apotek. Jakarta: Kementerian Kesehatan Republik Indonesia.

6. FIP/WHO. 2011. Guidelines on Good Pharmacy Practice: Standars for Quality of Pharmacy Services. Netherlands: International Pharmaceutical Federation.

7. Anonim, 2018. Profil Kabupaten Karangasem. Karangasem: Satgas Randal Kabupaten Karangasem. 